\title{
ANALISIS KADAR LOGAM BERAT TEMBAGA (Cu) DAN KADMIUM (Cd) PADA IKAN KAKAP (Lates calcalifer) ASAL TAKALAR SECARA SPEKTROFOTOMETRI SERAPAN ATOM
}

\author{
A. Muflihunna \\ Fakultas Farmasi Universitas Muslim Indonesia \\ Email : amchund124@gmail.com
}

\begin{abstract}
The analysis of Cuprum (Cu) and Cadmium (Cd) content had been done of Kakap fish (Lates calcalifer) in Tope Jawa and Satanga Island. This research aim to analyse and determine the quantity of Cuprum (Cu) and Cadnium (Cd) of Kakap fish (Lates calcalifer) by Atomic Absorption Spectrophotometry (AAS). This research was done by dry destruction both types of the metal, then the result of destruction dissolved in acid. Its result then analysed qualitative by specific reaktan and analysed quantitative by Atomic Absorption Spectrophotometry of wavelength 324,8 $\mathrm{nm}$ for the Cuprum and 228,8 $\mathrm{nm}$ for the Cadmium. The result of research obtained that Kakap fish in Tope Jawa and Satanga Island contain the metal of Cuprum (Cu) and Cadmium (Cd) but not exceed the boundary of rate maximum specified by DITJEN POM
\end{abstract}

Key Word: Cuprum (Cu), Cadmium (Cd), Kakap fish and AAS

\section{PENDAHULUAN}

Pencemaran logam berat
merupakan salah satu bahan
pencemar yang berasal dari limbah
industri. Limbah industri yang mengandung logam berat akan masuk ke wilayah perairan kemudian logam berat tersebut akan diencerkan sehingga kekuatan mencemarnya akan menjadi lemah, namun bila bahan cemarnya tersebut secara terus-menerus memasuki wilayah perairan secara perlahan-lahan akan menjadi penumpukan logam berat yang akan terjadi pada sediment laut. Hal ini akan mempengaruhi berbagai organisme di sekitarnya (Darmono, 1995).

Logam Cd merupakan unsur yang banyak digunakan sebagai lapisan tahan korosi pada baja dan plastik, pewarna, dan elektronik, baterai, dimana unsur ini dapat mengakibatkan berbagai disfungsi organ dan metabolisme. Pada kadar Cd yang tinggi dapat menghalangi kerja paru-paru bahkan dapat menyebabkan kanker paru-paru. 
Logam $\mathrm{Cu}$ merupakan logam berat essensial yang dibutuhkan oleh tubuh dalam jumlah yang kecil, namun bila jumlah yang masuk ke dalam tubuh berlebihan akan berubah fungsi menjadi zat racun bagi tubuh. Keracunan $\mathrm{Cu}$ dapat menyebabkan gangguan pada jalur pernapasan (Frank, 1991).

Ikan kakap sangat digemari oleh masyarakat luas, tidak saja di Indonesia, melainkan juga di negaranegara Asia lainnya, di Australia, dan di mana saja jenis ikan kakap (Lates calcalifer) ini ditemukan (Asikin, 1985).

Pencemaran habitat ikan kakap dapat memungkinkan terjadinya kontaminasi logam berat berbahaya Cd dan $\mathrm{Cu}$ pada tubuh ikan tanpa mengakibatkan kematian. Hal ini menjelaskan bahwa ikan kakap (Lates calcalifer) dapat hidup dengan berbagai kondisi habitat (Dinata, 2005).

Ikan kakap (Lates calcalifer) yang telah terkontaminasi oleh logam berat dikonsumsi oleh manusia sehingga dapat mengasup logam berat berbahaya tersebut. Hal ini dapat mengakibatkan toksisitas baik akut maupun kronik. Oleh karena itu kandungan logam berat $\mathrm{Cu}$ dan $\mathrm{Cd}$ perlu diperiksa atau dianalisis pada ikan kakap untuk mengetahui sejauh mana kontaminasi telah terjadi. Menurut DITJEN POM, standar maksimum kadar logam berat $\mathrm{Cd}$ dalam makanan adalah $2 \mathrm{mg} / \mathrm{kg}$ sedangkan $\mathrm{Cu}$ adalah $20 \mathrm{mg} / \mathrm{kg}$.

Berdasarkan hal-hal tersebut di atas, maka dilakukan penelitian analisis kadar logam berat tembaga (Cu) dan kadmium (Cd) pada ikan kakap (Lates calcalifer) menggunakan metode Spektrofotometri Serapan Atom (SSA).

\section{METODE PENELITIAN}

\section{A. Penyiapan sampel}

Sampel ikan kakap (Lates calcalifer) diambil di Takalar yaitu Tope Jawa dan pulau Satanga. Sampel yang digunakan yaitu daging ikan kakap (Lates calcalifer) yang telah dicuci dengan air bersih dan dipotong kecil-kecil.

a. Ditimbang dengan teliti 5 gram sampel dalam cawan porselin kemudian di dekstruksi dengan cara pengabuan selama 4-5 jam pada suhu $500^{\circ} \mathrm{C}$ dalam tanur dan dibiarkan dingin dalam eksikator.

b. Abu dengan hati-hati ditambahkan $5 \mathrm{ml} \mathrm{HNO}_{3}$ pekat.

c. Kemudian kelebihan $\mathrm{HNO}_{3}$ diuapkan pada suhu $100-120^{\circ} \mathrm{C}$ pada Hot plate di dalam lemari 
asam, kemudian cawan porselin yang berisi sampel dimasukkan kembali ke dalam tanur dan diabukan selama 1 jam pada suhu $500^{\circ} \mathrm{C}$ lalu didinginkan.

d. Selanjutnya ditambahkan dengan $5 \mathrm{ml} \mathrm{HCl} 6 \mathrm{~N}$ kemudian disaring dalam labu tentukur 50 $\mathrm{ml}$ dan diencerkan hingga batas tanda dengan air suling.

e. Larutan sampel kemudian digunakan untuk uji kualitatif $\mathrm{Cu}$ dan Cd.

\section{B. Analisis Kualitatif}

\section{a. Analisis Kualitatif Logam Tembaga (Cu)}

1. Ke dalam tabung reaksi dimasukkan $1 \mathrm{ml}$ larutan sampel kemudian ditambahkan 3 tetes larutan ammonia $2 \mathrm{M}$

2. Ke dalam tabung reaksi dimasukkan $1 \mathrm{ml}$ larutan sample kemudian ditambahkan 3 tetes larutan KI $6 \mathrm{~N}$

\section{b. Analisis Kualitatif Logam} Kadmium (Cd)

1. Ke dalam tabung reaksi dimasukkan $1 \mathrm{ml}$ larutan sampel kemudian diteteskan larutan ammonia $2 \mathrm{M}$

2. Ke dalam tabung reaksi dimasukkan $1 \mathrm{ml}$ larutan sampel kemudian diteteskan larutan $\mathrm{NaOH} 2 \mathrm{M}$

3. Ke dalam tabung reaksi dimasukkan $1 \mathrm{ml}$ larutan sampel kemudian diteteskan larutan Kalium lodida $6 \mathrm{~N}$

\section{Analisis Kuantitatif}

\section{a. Analisis Kuantitatif Logam} Tembaga (Cu)

1. Pembuatan Larutan Baku Tembaga Sulfat (CuSO $_{4.5 \mathrm{H} 2 \mathrm{O})}$

Ditimbang dengan teliti 0,3972 gram tembaga sulfat (CuSO $4.5 \mathrm{H} 2 \mathrm{O}$ ), lalu dimasukkan ke dalam labu tentukur $100 \mathrm{ml}$ dan dan dicukupkan volumenya dengan air suling hingga batas. Selanjutnya dibuat larutan baku dengan konsentrasi 2 ppm, 4 ppm, 6 ppm, 8 ppm dan 10 ppm.

2. Pembuatan Kurva Baku Logam Tembaga $(\mathrm{Cu})$

1. Larutan baku dengan konsentrasi 2 ppm, 4 ppm, 6 ppm, 8 ppm dan $10 \mathrm{ppm}$.

2. Masing-masing diukur absorbannya menggunakan alat spektrofotometri serapan atom pada panjang 


gelombang $324,8 \mathrm{~nm}$
dengan lampu katoda
Cu. Kurva baku dibuat
dengan cara memplot
nilai absorban terhadap
konsentrasi larutan
(ppm).

\section{Pengukuran}

Serapan

Tembaga (Cu) Dalam Sampel

Larutan sampel

diukur absorbannya dengan alat spektrofotometri serapan atom pada panjang gelombang $324,8 \quad \mathrm{~nm}$ dengan menggunakan lampu katoda $\mathrm{Cu}$

b. Analisis Kuantitatif Logam Kadmium (Cd)

1. Pembuatan Larutan Baku Kadmium Klorida
$\left(\mathrm{CdCl}_{2} \cdot \mathrm{H}_{2} \mathrm{O}\right)$

Ditimbang dengan teliti 0,1792 gram kadmium klorida $\left(\mathrm{CdCl}_{2} \cdot \mathrm{H}_{2} \mathrm{O}\right)$, lalu dimasukkan ke dalam labu tentukur $100 \mathrm{ml}$ dan dan dicukupkan volumenya dengan air suling hingga batas. Selanjutnya dibuat larutan baku dengan konsentrasi 2 ppm, 4 ppm, 6 ppm, 8 ppm dan 10 ppm.

2. Pembuatan Kurva Baku Logam Kadmium (Cd)

1. Larutan baku dengan konsentrasi 2 ppm, 4 ppm, 6 ppm, 8 ppm dan 10 ppm.

2. Masing-masing diukur absorbannya menggunakan alat spektrofotometri serapan atom pada panjang gelombang 228,8 $\mathrm{nm}$ dengan lampu katoda Cd. Kurva baku dibuat dengan cara memplot nilai absorban terhadap konsentrasi larutan (ppm).

3. Pengukuran Serapan Kadmium (Cd) Dalam Sampel

Larutan sampel diukur absorbannya dengan alat spektrofotometri serapan atom pada panjang gelombang 228,8 $\mathrm{nm}$ dengan menggunakan lampu katoda Cd. 


\section{HASIL PENELITIAN}

Tabel 1. Hasil identifikasi kualitatif logam tembaga (Cu) dan Cadnium (Cd) pada sampel ikan kakap (Lates calcalifer)

\begin{tabular}{ccccc}
\hline Logam & Pereaksi & Pustaka & Sampel & Ket. \\
\hline \multirow{2}{*}{ Tembaga $(\mathrm{Cu})$} & Ammonia & $\downarrow$ biru & $\downarrow$ biru & + \\
& Kalium iodida & $\downarrow$ coklat & $\downarrow$ coklat & + \\
\hline \multirow{2}{*}{ Cadnium $(\mathrm{Cd})$} & Ammonia & $\downarrow$ putih & $\downarrow$ putih & + \\
& Natrium hidroksida & $\downarrow$ putih & $\downarrow$ putih & + \\
& Kalium iodida & Tidak ada $\downarrow$ & Tidak ada $\downarrow$ & + \\
\hline
\end{tabular}

Tabel 2. Hasil analisis kuantitatif logam tembaga (Cu) dan cadmium (Cd) pada ikan kakap (Lates calcalifer) secara Spektrofotometri Serapan Atom pada Panjang Gelombang $324.8 \mathrm{~nm}$

\begin{tabular}{ccc}
\hline Lokasi & $\begin{array}{c}\text { Kadar Rata-rata Logam Tembaga } \\
(\mathbf{C u})(\mathbf{m g} / \mathbf{k g})\end{array}$ & $\begin{array}{c}\text { Kadar Rata-rata Logam } \\
\text { Kadmium }(\mathbf{C d})(\mathbf{m g} / \mathbf{k g})\end{array}$ \\
\hline Tope jawa & 1.8773 & 0.9363 \\
Pulau Satanga & 0.6795 & 0.7645 \\
\hline
\end{tabular}

\section{PEMBAHASAN}

Penelitian ini dilakukan dengan menganalisis kadar logam berat tembaga (Cu) dan kadmium (Cd) pada ikan kakap (Lates calcalifer) asal Takalar secara spektrofotometri serapan atom. Penelitian ini bertujuan menganalisis dan menentukan kadar logam berat tembaga (Cu) dan kadmium (Cd) pada ikan kakap (Lates calcalifer).

Pengambilan sampel ikan kakap (Lates calcalifer) dibagi menjadi 2 lokasi yaitu Tope Jawa dan Pulau Satanga dengan tujuan untuk mengetahui tingkat cemaran di kedua lokasi tersebut terhadap logam tembaga dan kadmium.

Pencemaran atau polusi adalah suatu kondisi yang telah berubah dari bentuk asal pada keadaan yang lebih buruk. Suatu lingkungan dikatakan tercemar apabila telah terjadi perubahan-perubahan dalam tatanan lingkungan itu sehingga tidak sama lagi dengan bentuk asalnya, sebagai akibat dari masuknya suatu zat atau benda asing kedalam tatanan lingkungan itu.

Sebelum di analisis sampel ikan kakap terlebih dahulu dibersihkan, selanjutnya dipotong kecil-kecil. Kemudian ditimbang sebanyak 5 gram kemudian didekstruksi dengan cara diabukan selama 4-5 jam pada suhu $500^{\circ} \mathrm{C}$ di dalam tanur. Metode dekstruksi yang digunakan adalah dekstruksi kering karena pada umumnya metode ini digunakan untuk analisis logam. Tujuan dilakukan 
dekstruksi ini adalah untuk menghilangkan senyawa-senyawa organik yang terdapat dalam sampel. Abu yang diperoleh dilarutkan dengan $5 \mathrm{ml} \quad \mathrm{HNO}_{3} \mathrm{P}$ dengan tujuan menyempurnakan proses dekstruksi dengan menghilangkan senyawasenyawa organik yang masih terdapat dalam abu. Sisa $\mathrm{HNO}_{3}$ dihilangkan dengan cara pemenasan di atas hot plate dalam lemari asam untuk mencegah terhirupnya $\mathrm{NO}_{2}$ (racun). Lalu ditambahkan $5 \mathrm{ml} \mathrm{HCl} 6 \mathrm{~N}$ dengan tujuan untuk melarutkan sampel yang terdapat dalam abu kemudian disaring dengan kertas saring lalu filtratnya diambil dan dimasukkan ke dalam labu tentukur 50 $\mathrm{ml}$ kemudian dicukupkan volumenya dengan air suling hingga batas tanda dan selanjutnya dianalisis. Filtrat yang diperoleh dianalisis secara kualitatif dan kuantitatif.

Hasil analisis uji kualitatif menunjukkan bahwa sampel positif mengandung logam $\mathrm{Cu}$ dengan menggunakan pereaksi spesifik yaitu $\mathrm{NH}_{3}$ menghasilkan endapan biru dan $\mathrm{KI}$ menghasilkan endapan coklat sedangkan sampel positif mengandung logam $\mathrm{Cd}$ yaitu $\mathrm{NaOH}$ menghasilkan endapan putih, $\mathrm{NH}_{3}$ menghasilkan endapan putih, KI menghasilkan larutan kuning yang tidak membentuk endapan tetapi karena pada sampel tidak hanya mengandung satu logam saja maka endapan putih dan larutan kuning yang tidak membentuk endapan tidak nampak ketika ditambahkan $\mathrm{NH}_{3}$ dan KI. Hasil penelitian kuantitatif pada tabel 3 menunjukkan bahwa kadar rata-rata logam tembaga pada ikan kakap di Tope jawa sebesar 1.8773 $\mathrm{mg} / \mathrm{kg}$ dan di pulau satanga sebesar $0.6795 \mathrm{mg} / \mathrm{kg}$. Sedangkan kadar ratarata logam kadmium pada ikan kakap di Tope jawa sebesar $0.9363 \mathrm{mg} / \mathrm{kg}$ dan di pulau satanga sebesar 0.7645 $\mathrm{mg} / \mathrm{kg}$. Dari tabel dapat bahwa kadar logam tembaga dan kadmium lebih besar pada lokasi Tope jawa hal ini di sebabkan karena logam $\mathrm{Cu}$ dan $\mathrm{Cd}$ banyak ditemui pada limbah rumah tangga seperti baterai, plastik, korosi pipa-pipa air, deterjen, kabel, dan pembuangan dari kapal-kapal nelayan.

Berdasarkan hasil analisis bahwa kandungan logam tembaga (Cu) dan kadmium (Cd) pada ikan kakap (Lates calcalifer) yang di ambil dari Tope jawa dan pulau satanga tidak melebihi ambang batas yang ditetapkan. Menurut DITJEN POM, standar maksimum kadar logam berat $\mathrm{Cd}$ dalam makanan adalah $2 \mathrm{mg} / \mathrm{kg}$ sedangkan logam berat $\mathrm{Cu}$ adalah 20 $\mathrm{mg} / \mathrm{kg}$. 


\section{KESIMPULAN}

Berdasarkan hasil penelitian yang telah dilakukan, maka dapat disimpulkan bahwa kadar rata-rata logam tembaga (Cu) dan kadmium (Cd) pada ikan kakap (Lates calcalifer) yang terdapat di Tope jawa dan pulau Satanga tidak melebihi kadar yang ditetapkan oleh DITJEN POM. Disarankan agar dilakukan penelitian mengenai cemaran logam lainnya dalam perairan takalar.

\section{DAFTAR PUSTAKA}

Asikin, Drs. 1995. Budidaya Ikan Kakap. Penerbit : Swadaya.

Cantle, E., John. 1982. Atomic Absorbtion Spectrometry. Elsevier Scientific Publishing Company Amsterdam, Oxford : Newyork

Darmono. 1995. Logam Dalam Sistem Biologi Makhluk Hidup. U I Press. Jakarta.

Darmono. 2001. Lingkungan Hidup dan Pencemaran: Hubungannya dengan Toksikologi Senyawa Logam. UI Press : Jakarta.

Day. Jr, Al. Underwood. 1994. Analisis Kimia Kuantitatif. Penerbit Erlangga : Surabaya.

Dian hanjaya. 1989. Distribusi Logam Berat $\mathrm{Cd}, \mathrm{Cu}, \mathrm{Pb}$, dan $\mathrm{Zn}$ dalam sedimen Permukaan Laut Dangkal. Skripsi. Fakultas Matematika Dan IImu Pengetahuan Alam, Universitas Hasanuddin, Makassar.
Dinata, Arda. 2005. Waspadai Pengaruh Toksisitas pada Ikan. Http//www.pikiran rakyat.com.

Ganiswara. G. Sulistia. 1995. Farmakologi dan Terapi. Edisi IV. Bagian Farmakologi Fakultas Kedokteran UI : Jakarta.

Gufran, M dan H. Kordi K. 1997. Budidaya Ikan Kakap. Penerbit: Dahara Prize

Hamidah. 1980. Pengaruh Logam Berat Terhadap Lingkungan. Pew, Oseana.

Jalaluddin, Noor. 1993. Makro, Mikro dan Beberapa Logam Berbahaya. Kursus Instrumental Kimia Analitik, Proyek Pengembangan dan Percepatan PT, Dirjen PT Depdikbud : Ujung Pandang.

Khopkar, S, M. 1990. Konsep Dasar Kimia Analitik. Terjemahan oleh A. Saptorahardjo, penerbit Universitas Indonesia. UimPress : Jakarta.

Lu, C, Frank. 1991. Toksikologi Dasar. Terjemahan oleh Edi Nugroho. Penerbit UI Press.

Lu, C., Frank. 2006. Toksikologi Dasar, Asas, Organ Sasaran, dan Penilaian Risiko. Edisi II. Terjemahan Oleh Edi Nugroho. Penerbit Universitas Indonesia. Jakarta.

Nasoetion, Hakim, A dan Karyadi, Darnin. 1988. Mineral. PT. Gramedia : Jakarta.

Palar, H. 1994. Pencemaran dan Toksikologi Logam Berat. Rineka Cipta : Jakarta. 
Analisis Kadar Logam Berat Tembaga (Cu) Dan Kadmium (Cd) Pada Ikan Kakap

Pardjoko. 2001. Klasifikasi Ikan Kakap. $\mathrm{Http} / / \mathrm{www}$. google.com.

Svehla, G. 1990. Buku Teks Analisis Kulitatif Makro dan Semimikro. Terjemahan oleh Setiono dan Pudjaatmaka, Hanyana, A.
Penerbit PT. Kalman Media Pustaka : Jakarta.

The Merk Index, An Encyclopedia of Chemical. Drug and Biological. 1989. Merk and co. Inc. Rahway New Jersey : USA 